\title{
Intimate Partner Violence and Health Care-Seeking Patterns Among Female Users of Urban Adolescent Clinics
}

\author{
Elizabeth Miller · Michele R. Decker • Anita Raj • \\ Elizabeth Reed · Danelle Marable · Jay G. Silverman
}

Published online: 17 September 2009

(C) The Author(s) 2009. This article is published with open access at Springerlink.com

\begin{abstract}
To assess the prevalence of intimate partner violence (IPV) and associations with health care-seeking patterns among female patients of adolescent clinics, and to examine screening for IPV and IPV disclosure patterns within these clinics. A self-administered, anonymous, computerized survey was administered to female clients ages $14-20$ years $(N=448)$ seeking care in five urban adolescent clinics, inquiring about IPV history, reasons for seeking care, and IPV screening by and IPV disclosure to providers. Two in five (40\%) female urban adolescent clinic patients had experienced IPV, with 32\% reporting physical and $21 \%$ reporting sexual victimization. Among IPV survivors, $45 \%$ reported abuse in their current or most recent relationship. IPV prevalence was equally high among those visiting clinics for reproductive health concerns as among those seeking care for other reasons. IPV victimization was associated with both poor current health status (AOR 1.57, 95\% CI 1.03-2.40) and having foregone care in the past year (AOR 2.59, 95\% CI 1.20-5.58). Recent IPV victimization was associated only with past 12 month foregone care (AOR 2.02, 95\% CI 1.18-3.46). A
\end{abstract}

E. Miller $(\bowtie)$

Department of Pediatrics, UC Davis School of Medicine, Ticon II, 2516 Stockton Blvd., Rm 382, Sacramento, CA 95817, USA

e-mail: elizabeth.miller@ucdmc.ucdavis.edu

M. R. Decker · E. Reed · J. G. Silverman

Harvard School of Public Health, Boston, MA, USA

A. Raj

Boston University School of Public Health, Boston, MA, USA

D. Marable

MGH Center for Community Health Improvement,

Massachusetts General Hospital, Boston, MA, USA minority (30\%) reported ever being screened for IPV in a clinical setting. IPV victimization is pervasive among female adolescent clinic attendees regardless of visit type, yet IPV screening by providers appears low. Patients reporting poor health status and foregone care are more likely to have experienced IPV. IPV screening and interventions tailored for female patients of adolescent clinics are needed.

Keywords Intimate partner violence .

Adolescent dating violence $\cdot$ Sexual violence .

Physical violence $\cdot$ Adolescent health screening

\section{Background}

Physical and sexual violence by male intimate partners affects an estimated one in four U.S. women across the lifespan [1-3], and is associated with numerous negative physical, sexual, and mental health outcomes, as well as homicide [4-9]. Among adult women, clinical settings are recognized as strategic sites for identification and intervention [5, 10-13] based on high rates of IPV found among women seeking medical care at emergency departments $[14,15]$, primary care clinics [7, 12, 16, 17], and obstetrics/ gynecology and family planning clinics [18]. Consequently, the medical profession has developed policy and programmatic efforts to identify and assist abused women in such settings [19-21]. However, the potential utility of such an approach to assist the large population of adolescents victimized by partners has not been examined.

Epidemiologic studies demonstrate that the greatest risk for IPV occurs for females in mid to late adolescence [2, 22-24], with one in five high school girls reporting physical or sexual IPV victimization during their high school 
years [4]. Recent studies with adolescents and young adults document elevated rates of health risks and disease among IPV victims as compared to those without such IPV histories [4, 25-30], suggesting that clinical settings may represent a critical opportunity for reaching this population. However, IPV among adolescents is reported to be rarely identified by health care providers, and descriptions of IPV care-seeking patterns among adolescents remain limited [29, 31].

As adolescent health care utilization patterns differ significantly from those of adults [32], clinics specifically serving adolescents are strategic sites for adolescent health promotion, prevention, and intervention. Located in schools and community settings, primarily in low-income communities, adolescent clinics provide comprehensive adolescent health services, eliminating important barriers to health care faced by adolescents, such as concerns about confidentiality, lack of health insurance, and limited knowledge of the health care system [32-34]. Thus, adolescent clinics serve large numbers of adolescents who otherwise might not come into contact with health care providers. Consistent with adolescent health care utilization patterns, the majority of clients served in these adolescent clinics are female $[35,36]$.

Prior research conducted with young adult females in clinical settings, including family planning clinic users [18, 37, 38], sexually-active African-American girls from adolescent clinics and low income communities [24], and programs for adolescent mothers $[39,40]$, has documented higher IPV prevalence estimates (20-38\%) than are typically identified in the school population. These data suggest that clinics serving adolescents may be critical access points for identifying and assisting adolescent IPV victims. Experiencing IPV may result in particular health concerns that affect health care-seeking patterns, such as need for pregnancy testing or sexually transmitted infection treatment. Another possibility emerging from the adolescent health literature is that youth who seek care at adolescent clinics may simply represent a sub-sample of teens experiencing a range of poor health behaviors including IPV. Examining the prevalence and characteristics of IPV among the broader population of adolescent females seeking care in adolescent clinics, as well as care-seeking patterns associated with such violence, is necessary to guide the development of IPV identification and intervention programs in this setting and to inform whether such programs should be targeted (e.g., focused on reproductive or sexual health patients) or more broadly implemented.

The purpose of the current study was to (1) assess the prevalence of IPV and associations with health care-seeking among a diverse sample of female patients of urban adolescent clinics, and (2) examine prevalence of IPV screening by and disclosure to clinical providers.

\section{Methods}

\section{Sample and Data Collection}

The current study was conducted via an anonymous, crosssectional survey of English and Spanish-speaking females ages 14-20 years seeking health care in five clinics providing confidential services to adolescents in urban neighborhoods of Greater Boston. Two clinics were located in public schools, one was located within a community health center, and two were based in other community settings (a post office building and a youth center). Upon arrival to the clinic, adolescent females seeking health services of any type were screened for age eligibility by trained research staff. Those ages 14-20 years and indicating an interest in participating were escorted to a private area of the clinic for consent procedures and survey administration; consent was obtained verbally to protect participant anonymity. As participants were receiving confidential clinic services, parental consent for participation was waived.

Data were collected via ACASI (Audio Computer Assisted Survey Instrument), a self-administered computer program that allows participants to complete surveys on a laptop computer with questions read aloud to them over headphones. With demonstrated ability to improve data collection concerning sensitive behaviors [41, 42], ACASI is recommended as the best method for obtaining valid and reliable data on IPV [43]. Following survey completion, all participants were asked by the research assistant whether they had any concerns that emerged while answering the survey questions and whether they would like to speak with a clinic provider. On-site counseling was available at all participating clinics, however, no participants indicated survey-related distress. Each participant also received a list of local relevant resources (e.g., violence victimization support services, mental health services) and a $\$ 20$ pre-paid debit card to thank them for their time. All consent and data collection materials were conducted and provided in English or Spanish based on the preference of the participant. Research assistants recruited participants a few times a week over a 3-4 month period at each site. Data collection took place from April to December 2006. All study procedures were reviewed and approved by human subjects research committees at the Partners Health Care System, Cambridge Health Alliance, and the Harvard School of Public Health.

Seven hundred and forty-seven female clients were recruited based on meeting age eligibility criteria and 495 agreed to complete the survey, resulting in a participation rate of $66 \%$. The primary reason for non-participation was lack of time. Of the 495, 9 participants indicated that they would not provide honest answers based on a screener question (shown to improve data quality in psychiatric 
surveys) [44], and 38 provided incomplete data regarding outcomes of interest, resulting in a final analytic sample of 448.

\section{Measures}

Single items assessed demographic characteristics including age, race/ethnicity, education level, and immigrant status, as well as participants' reason for current visit to the clinic, past year foregone health care (i.e., having needed but not sought care), and self-reported health status. Foregone care was indicated by a positive response to "In the past year, have you ever thought you should go to a doctor, nurse, or emergency room, but did not?"[45] A five-point Likert scale item assessed general perception of health status: "Would you say that in general your health is ...?" with responses grouped into three categories"excellent," "very good-good," and "fair-poor"[46, 47].

Questions specific to intimate partners were referred to in the survey as "questions about your sexual and dating relationships," defined as "someone you were dating or going out with" or "regularly having sex with" (for those questions that referred to sexual behaviors). Lifetime histories of physical and sexual violence victimization by current or former intimate partners were assessed via six items for each of these two forms of IPV (i.e., 12 items total). Assessments included items modified from the conflict tactics scales-2 (CTS-2) [48] and the sexual experiences survey [49] (see Table 1).

Additional single items were utilized to assess whether a doctor or nurse had ever asked the participant about IPV and, for those who had experienced IPV, whether they had disclosed this to the health care provider. Participants were also asked whether they thought health care providers should ask their adolescent patients about IPV experiences.

\section{Analyses}

Lifetime prevalence estimates of physical and sexual IPV were calculated, as well as prevalence of IPV in their current or most recent relationship. Differences in experiences of physical and sexual IPV based on demographic characteristics were assessed via chi-square analyses; significance for all analyses was set at $p<.05$. Crude and adjusted logistic regression models were constructed to assess the associations of IPV experiences (both lifetime prevalence and IPV in current or most recent relationship) with reason for clinic visit, foregone care, and self-reported health status; adjusted analyses included demographics associated with IPV in chi-square analyses. Descriptive statistics were calculated for IPV screening and disclosure experiences within the health care setting. All logistic regression models included recruitment site as a potential
Table 1 Lifetime and current/recent prevalence of IPV victimization among adolescent females seeking clinical care $(N=448)$

\begin{tabular}{|c|c|}
\hline & $\%$ \\
\hline \multicolumn{2}{|l|}{ Physical Violence Cronbach's alpha 0.81} \\
\hline $\begin{array}{l}\text { Push, slap, punch, hit, kick, shove or throw something } \\
\text { at* }\end{array}$ & \\
\hline Slam against wall* & 20 \\
\hline Choke or beat up* & 11 \\
\hline Used knife or gun against* & \\
\hline $\begin{array}{l}\text { Received injury (sprain, bruise, cut, broken bone) } \\
\text { during fight* }\end{array}$ & \\
\hline Had to go to doctor because of fight* & \\
\hline Any physical violence victimization ever & \\
\hline \multicolumn{2}{|l|}{ Sexual Violence Cronbach's alpha 0.80} \\
\hline $\begin{array}{l}\text { Insisted (without using force or threats) on having sex } \\
\text { (oral, vaginal, or anal) when you didn't want to* }\end{array}$ & \\
\hline $\begin{array}{l}\text { Used threats to make you have sex (oral, vaginal, } \\
\text { or anal)* }\end{array}$ & \\
\hline $\begin{array}{l}\text { Used force to make you have sex (oral, vaginal, } \\
\text { or anal)* }\end{array}$ & \\
\hline $\begin{array}{l}\text { Insisted (without using force or threats) that you do } \\
\text { something sexual to make you do something sexual } \\
\text { (besides having oral, vaginal or anal sex) when } \\
\text { you didn't want to* }\end{array}$ & 13 \\
\hline $\begin{array}{l}\text { Used threats to make you do something sexual (besides } \\
\text { having oral, vaginal or anal sex)* }\end{array}$ & \\
\hline $\begin{array}{l}\text { Used force to make you do something sexual (besides } \\
\text { having oral, vaginal or anal sex)* }\end{array}$ & 2 \\
\hline Any sexual violence victimization ever & 21 \\
\hline Any physical or sexual violence victimization ever & 40 \\
\hline IPV occurred in current or most recent relationship & 18 \\
\hline
\end{tabular}

* Modified from revised conflict tactics scale (CTS2) [48]

confounder. Statistical analyses were conducted using SAS Version 9 [50].

\section{Results}

\section{Sample Characteristics}

The mean age of participants was 17.0 years $(\mathrm{SD}=1.7)$. Approximately 1 in 3 (34\%) were non-Hispanic White, 26\% were African American, 34\% were Hispanic, and 3\% were Asian. These percentages were consistent with the overall patient demographic characteristics reported by the clinics. One in $6(16 \%)$ participants were born outside the U.S. Sixty-four percent were currently in high school; $29 \%$ were either in college or finished high school. Most $(82 \%)$ were living with parents or family; $11 \%$ were currently living with friends, between homes, or reported other living situations (e.g., homeless, foster home). Seven percent reported living with their male partner. 
Table 2 Demographics and associations with IPV victimization

\begin{tabular}{|c|c|c|c|c|c|}
\hline & Sample ${ }^{\S} \%$ & $\begin{array}{l}\text { Lifetime Physical } \\
\text { or Sexual IPV }{ }^{\dagger} \%\end{array}$ & $\begin{array}{l}\mathrm{AOR} * * \\
(95 \% \mathrm{CI})\end{array}$ & $\begin{array}{l}\text { IPV in current or most } \\
\text { recent relationship***\% }\end{array}$ & $\begin{array}{l}\mathrm{AOR} * * \\
(95 \% \mathrm{CI})\end{array}$ \\
\hline \multicolumn{6}{|l|}{ Age group } \\
\hline $14-15$ & 19.6 & 34.1 & -ref- & 13.6 & -ref- \\
\hline $16-17$ & 42.4 & 43.7 & $1.49(0.68,3.28)$ & 18.4 & $0.92(0.32,2.60)$ \\
\hline $18+$ & 38.0 & 38.8 & $1.77(0.65,4.84)$ & 20.0 & $1.03(0.28,3.78)$ \\
\hline \multicolumn{6}{|l|}{ Race/ethnicity } \\
\hline White & 33.9 & 42.4 & -ref- & 15.2 & -ref- \\
\hline Black/African American & 26.1 & 37.1 & $0.73(0.40,1.32)$ & 19.0 & $1.05(0.50,2.21)$ \\
\hline Latina & 34.2 & 38.2 & $0.84(0.50,1.43)$ & 16.5 & $1.05(0.3,2.10)$ \\
\hline Other & 5.7 & 50.0 & $1.58(0.63,3.94)$ & 38.5 & $4.07(1.49,11.14)$ \\
\hline \multicolumn{6}{|l|}{ Nativity } \\
\hline US born & 83.7 & 41.9 & $1.73(0.93,3.24)$ & 18.4 & $1.27(0.57,2.81)$ \\
\hline Foreign born & 16.3 & 30.1 & -ref- & 16.4 & -ref- \\
\hline \multicolumn{6}{|l|}{ Grade in school } \\
\hline 9 th or less & 12.8 & 33.3 & -ref- & 12.3 & -ref- \\
\hline 10th & 14.5 & 41.5 & $1.01(0.43,2.34)$ & 16.9 & $1.37(0.42,4.47)$ \\
\hline 11th & 20.4 & 41.8 & $0.83(0.32,2.17)$ & 19.8 & $1.74(0.48,6.35)$ \\
\hline 12 th & 16.6 & 44.6 & $0.93(0.33,2.60)$ & 16.2 & $1.35(0.33,5.57)$ \\
\hline GED program (not in a Grade) & 7.2 & 46.9 & $0.82(0.32,2.17)$ & 28.1 & $1.95(0.40,5.57)$ \\
\hline $\begin{array}{l}\text { Graduated high school (college } \\
\text { or not in school) }\end{array}$ & 28.6 & 35.9 & $0.49(0.16,1.53)$ & 18.8 & $1.27(0.27,5.91)$ \\
\hline \multicolumn{6}{|l|}{ Living situation } \\
\hline Living with parents or family & 82.1 & 38.4 & -ref- & 16.1 & -ref- \\
\hline Living with partner & 6.7 & 40.0 & $1.23(0.53,2.88)$ & 22.3 & $1.39(0.50,3.84)$ \\
\hline $\begin{array}{l}\text { Living with friends, between homes, } \\
\text { child protective services, foster care, } \\
\text { or other }\end{array}$ & 11.2 & 50.0 & $1.55(0.82,2.95)$ & 28.0 & $1.58(0.75,3.33)$ \\
\hline
\end{tabular}

$I P V$ intimate partner violence

Boldface type indicates $p$ value $<0.05,95 \%$ confidence intervals do not cross 1.0

$\S$ Column percent

$\dagger$ Row percent

** Adjusted for all variables in table, recruitment site, and all variables in Table 3

Prevalence of Intimate Partner Violence

Forty percent reported ever experiencing some form of physical or sexual violence from a male intimate partner, with $32 \%$ reporting physical IPV, and $21 \%$ reporting sexual IPV. (Table 1) One quarter (25\%) of all participants reported being hit; $11 \%$ reported being choked, and $2 \%$ reported that a knife or gun had been used against them by an intimate partner. Slightly more than 1 in 7 (15\%) adolescent girls reported receiving an injury as the result of a fight with a partner. The most common forms of sexual violence included male partners insisting on having sexual intercourse or doing something sexual when a participant did not want to (16 and $13 \%$, respectively). Smaller percentages of adolescent clinic clients reported male partners' use of threats to make them have sex or do something else sexually (4 and 5\%, respectively), or being forced to have sex or participate in non-penetrative sexual activity against their will (4 and 3\%, respectively). Forty-five percent of those participants indicating histories of IPV ( $n=179$ ) reported IPV occurring in their current or most recent relationship (18\% of the total sample).

Associations of IPV Experiences with Demographics and Health Status

Experiences of IPV did not differ based on demographics assessed, with the exception of race/ethnicity; those grouped as 'other' (includes smaller percentages of Asian, Pacific Islander, Native American and youth describing themselves as 'other') were at higher risk for experiencing IPV in their current or most recent relationship. 
Table 3 Care-seeking patterns and associations with IPV victimization

\begin{tabular}{|c|c|c|c|c|c|}
\hline & Sample $^{\S} \%$ & $\begin{array}{l}\text { Lifetime physical } \\
\text { or sexual IPV } \text { IP }^{\dagger}\end{array}$ & $\mathrm{AOR}^{* *}(95 \% \mathrm{CI})$ & $\begin{array}{l}\text { IPV in current or most } \\
\text { recent relationship }{ }^{\dagger} \%\end{array}$ & $\overline{\mathrm{AOR} * *(95 \% \mathrm{CI})}$ \\
\hline \multicolumn{6}{|l|}{ Reason for visit } \\
\hline Annual visit/checkup/other & 37.1 & 36.1 & -ref- & 15.7 & -ref- \\
\hline Pregnancy test or EC & 13.6 & 41.0 & $1.08(0.55,2.10)$ & 23.0 & $1.72(0.76,3.93)$ \\
\hline Other reproductive health* & 36.6 & 39.6 & $1.10(0.65,1.86)$ & 15.2 & $1.07(0.54,2.13)$ \\
\hline STI/HIV testing or symptoms & 10.3 & 47.8 & $1.39(0.68,2.85)$ & 28.3 & $2.03(0.87,4.75)$ \\
\hline Mental health & 2.5 & 63.6 & $1.97(0.50,7.80)$ & 27.3 & $1.24(0.26,6.02)$ \\
\hline \multicolumn{6}{|l|}{ Foregone care past 12 months } \\
\hline No & 64.2 & 34.8 & -ref- & 13.9 & -ref- \\
\hline Yes & 35.8 & 49.4 & $1.57(1.03,2.40)$ & 25.6 & $2.02(1.18,3.46)$ \\
\hline \multicolumn{6}{|l|}{ Self-rated health } \\
\hline Excellent & 23.5 & 34.3 & -ref- & 17.1 & -ref- \\
\hline Very good-good & 66.4 & 38.7 & $1.15(0.70,1.87)$ & 15.8 & $0.79(0.42,1.50)$ \\
\hline Fair-poor & 10.1 & 62.2 & $2.59(1.20,5.58)$ & 35.6 & $1.84(0.77,4.41)$ \\
\hline
\end{tabular}

$I P V$ intimate partner violence

Boldface type indicates $p$ value $<0.05,95 \%$ confidence intervals do not cross 1.0

$\S$ Column percent

$\dagger$ Row percent

* Contraception, other reproductive concerns (not pregnancy testing or EC)

** Adjusted for all variables in table, demographics (Table 2 above), and recruitment site

Reasons for Seeking Clinical Care, Self-Rated Health and IPV

In this adolescent female clinic sample, the primary reason for seeking care was for reproductive health concerns $(50 \%)$, including $14 \%$ seeking pregnancy testing or emergency contraception (Table 3). Ten percent sought testing or care for symptoms related to HIV or sexually transmitted infections, and $37 \%$ were attending for a regularly scheduled visit. In adjusted analyses, no statistically significant differences in IPV prevalence were found based on reason for health care visit.

More than 1 in $3(36 \%)$ of respondents reported not seeking care in the past 12 months for health concerns although they knew they should see a health care provider. Those reporting foregoing care were more likely to report having ever experienced IPV ever as well as in their current or most recent relationship compared with those who had not foregone care. Adolescent clinic users reporting fair to poor health were also more likely to report IPV ever than those reporting good or excellent health.

\section{IPV Screening and Disclosure Experiences}

Three-quarters $(75 \%)$ of all respondents felt that doctors and nurses should ask adolescents about relationships and dating, specifically about whether they were being hurt or felt unsafe in the relationship (Table 4). Those who had experienced IPV were significantly more likely to support screening by health care providers. Only $30 \%$ of participants reported that a nurse or doctor had ever asked them about being hurt or feeling unsafe in a dating relationship; this number was significantly higher among those reporting experiences of IPV (49\%). Of participants with a history of IPV, 45\% reported being screened for IPV by a doctor or nurse while in an abusive relationship; $21 \%$ of those screened while in an abusive relationship reported that they disclosed this abuse to the health care provider. The most common reasons for non-disclosure were feeling it was none of the provider's business (34\%), embarrassment (32\%), fear of partner's anger (20\%), fear of providers telling parents (19\%), feeling that it was 'not a big deal' (24\%), and fear of providers reporting the abuse to child protective services $(12 \%)$.

\section{Discussion}

Two in five adolescent females attending adolescent clinics reported ever experiencing physical or sexual violence from an intimate partner. The prevalence of IPV in this clinical sample is approximately two-fold higher than estimates from community and school based samples. Further, among those who ever experienced IPV, just under half reported that violence occurred in their current or most recent relationship. These results underscore that 
Table 4 Screening for IPV by health care provider and IPV disclosure $(N=448)$

\begin{tabular}{|c|c|c|c|}
\hline & Sample ${ }^{\S} \%$ & $\begin{array}{l}\text { Any physical or } \\
\text { sexual IPV } \%\end{array}$ & No IPV ${ }^{\S} \%$ \\
\hline \multicolumn{4}{|l|}{ Screening recommendations } \\
\hline $\begin{array}{l}\text { "Yes" to "Should doctors and nurses ask teens about relationships and dating, } \\
\text { specifically about whether they are being hurt or feeling unsafe in the relationship?" }\end{array}$ & 75.0 & $87.4^{*}$ & 66.8 \\
\hline \multicolumn{4}{|l|}{ Screening experiences } \\
\hline $\begin{array}{l}\text { "Yes" to "Have you ever been asked by a doctor or nurse whether you were being } \\
\text { hurt or felt unsafe in a dating relationship?" }\end{array}$ & 29.5 & $48.8^{*}$ & 16.8 \\
\hline $\begin{array}{l}\text { "Yes" to "Have you ever been asked by a doctor or nurse whether you were being } \\
\text { hurt or felt unsafe in a dating relationship while in a dating or sexual relationship } \\
\text { with someone who was hurting you (emotionally, physically, or sexually)?" }\end{array}$ & & 44.8 & N/A \\
\hline \multicolumn{4}{|l|}{ Disclosure experiences } \\
\hline $\begin{array}{l}\text { "Yes" to "When you were asked, did you tell the doctor or nurse that someone you } \\
\text { were dating or going out with was hurting you?"** }\end{array}$ & & $20.5^{*}$ & N/A \\
\hline \multicolumn{4}{|l|}{$I P V$ intimate partner violence } \\
\hline \multicolumn{4}{|l|}{$\S$ Column percent } \\
\hline \multicolumn{4}{|l|}{${ }^{\dagger}$ Row percent } \\
\hline$* p<0.001$ & & & \\
\hline
\end{tabular}

adolescent clinics can serve as a critical site for identifying adolescent IPV, and for offering resources, referrals, and otherwise intervening to assist young women in danger.

Approximately one in nine females reported having ever been choked, and one in seven having sustained an injury from a dating partner. One in five were sexually victimized in the context of a relationship. These results call for intensive education of health care providers caring for adolescents to prepare them to discuss IPV, including sexual violence, in the lives of their young patients and to provide care to minimize the likelihood of further abuse.

In addition, over one-third of girls ages 14-15 years have experienced violence from a partner. This suggests that interventions, both clinical and prevention programs, must begin prior to the high school years. Further, the high prevalence of IPV across age groups underscores the importance of screening for partner violence among all adolescents, including those of relatively young age.

Although, consistent with prior studies [24, 37, 38], IPV prevalence was found to be high among girls seeking reproductive and sexual health services, such young women were not at greater risk for IPV as compared to those seeking care for other reasons. Thus, female users of adolescent clinics appear to be at high risk for IPV victimization regardless of reason for seeking care. Based on the present findings, IPV intervention efforts in these settings should be broad-based, and not focused solely on reproductive or sexual health. Notably, those clinic users who reported past year foregone care or who rated their overall health as relatively poor were more likely to report having ever experienced IPV. Those who reported foregoing care were also more likely to report IPV in their current or recent relationship. This underscores the potential importance of identifying those adolescents experiencing IPV as a means to provide needed clinical care and support services. Beyond foregone care and reporting poor health, adjusted analyses identified no additional risk markers or 'clinical red flags' for IPV victimization. Thus, current findings provide little support for an IPV-specific clinical profile that would facilitate selection of those individuals who should be prioritized for screening. At least among those adolescent females seeking care at these teen-specific clinics, universal screening and intervention for all comers to the clinic regardless of age, race/ethnicity, and reason for seeking care are indicated.

Further highlighting the need for improvements in this area of clinical practice, less than a third of female adolescent patients were ever screened by a health care provider for experiences of IPV. However, the majority stated they would want their health care provider to ask about the topic. Interestingly, participants who had experienced IPV were more likely to report having been asked about IPV, although the percentage screened was still less than half. This may represent heightened sensitivity or recall towards IPV related questions based on their experiences, or actual selective screening by providers based on signs of abuse. Regardless, these data point toward a critical unmet need regarding clinical care for adolescents experiencing IPV. The reasons for non-disclosure offered by participants, including fear of broader disclosure and embarrassment, also highlight the potential benefit of educating adolescent clinicians and clinic attendees regarding confidentiality, 
including limits of confidentiality, and the role of health care providers in providing supportive care.

The primary limitation for this study is the cross-sectional design (i.e., neither causality nor directionality can be assumed); longitudinal study is needed to clarify current findings. The association of IPV to foregone care and poor health status in particular merits further study, that is, whether and how current IPV might influence adolescent health care-seeking patterns. While the reliance on selfreport of IPV experiences is likely to introduce biases in assessment, prior studies on sensitive topics including violence indicate that utilizing ACASI improves data collection and reliability of self-reports [41, 42]. In addition, respondents were asked at the start of the survey whether they would be able to answer honestly; those who responded that they would not answer honestly were not included in the analyses. An additional study limitation is that the clinics chosen for this study were all from a single urban metropolitan area primarily serving clients from low income communities of color; thus, findings do not generalize to experiences of adolescent female clinic users from the broader population, particularly those living in rural or less impoverished areas.

\section{Conclusion}

This study documents a high prevalence of IPV victimization among female users of adolescent health clinics. Clinical implications of current findings include the need to develop, evaluate and implement IPV screening and intervention protocols for this population at high risk for experiencing IPV. In addition, health care providers who come in contact with adolescents should receive guidance to not only implement such protocols, but to also provide all adolescent clinic users with information on IPV and resources available for victims of such violence. Such screening and clinical interventions should include connections to IPV support and advocacy resources to assure provision of longer-term, expert assistance for this population. Development of adolescent-relevant and accessible IPV support, advocacy, and assistance resources should be considered priorities within adolescent medicine and related social services.

Acknowledgments Funding Support The research presented and the funding for this manuscript were made possible by grants from the National Center for Injury Prevention and Control/Centers for Disease Control (U36/CCU300430-23), the W.T. Grant Foundation Scholars Program (Grant\#2529), and Building Interdisciplinary Research Careers in Women's Health (BIRCWH, K12 HD051958; National Institute of Child Health and Human Development, Office of Research on Women's Health, Office of Dietary Supplements, National Institute of Aging). Additional Contributions We wish to thank the dedicated staff at Massachusetts General Hospital Revere and Chelsea Health Centers, Whittier Street Health Center, the Cambridge Health Alliance, and Roca, Inc. for their support and assistance with this project.

Open Access This article is distributed under the terms of the Creative Commons Attribution Noncommercial License which permits any noncommercial use, distribution, and reproduction in any medium, provided the original author(s) and source are credited.

\section{References}

1. World Health Organization Multi-Country Study on Women's Health and Domestic Violence against Women. Geneva, Switzerland: World Health Organization. (2003). http://www.who.int/ gender/violence/who_multicountry_study/en/. Accessed August 20,2008

2. Bureau of Justice Statistics. Intimate Partner Violence in the United States. Washington, DC: US Department of Justice, Office of Justice Programs. (2007). http://www.ojp.usdoj.gov/bjs/ intimate/ipv.htm. Accessed August 20, 2008.

3. Tjaden, P., \& Thoennes, N. (1998). Prevalence, incidence and consequences of violence against women: Findings from the National Violence Against Women Survey. Washington, DC: Department of Justice, National Institute of Justice.

4. Silverman, J. G., Raj, A., Mucci, L. A., \& Hathaway, J. E. (2001). Dating violence against adolescent girls and associated substance use, unhealthy weight control, sexual risk behavior, pregnancy, and suicidality. JAMA, 286, 572-579.

5. Campbell, J. C. (2002). Health consequences of intimate partner violence. Lancet, 359, 1331-1336.

6. Champion, H. L., Foley, K. L., DuRant, R. H., Hensberry, R., Altman, D., \& Wolfson, M. (2004). Adolescent sexual victimization, use of alcohol and other substances, and other health risk behaviors. Journal of Adolescent Health, 353, 21-28.

7. Hathaway, J. E., Mucci, L. A., Silverman, J. G., Brooks, D. R., Mathews, R., \& Pavlos, C. A. (2000). Health status and health care use of Massachusetts women reporting partner abuse. American Journal of Preventive Medicine, 19, 302-307.

8. Plichta, S. B. (2004). Intimate partner violence and physical health consequences: Policy and practice implications. Journal of Interpersonal Violence, 19, 1296-1323.

9. Decker, M. R., Martin, S. L., \& Moracco, K. E. (2004). Homicide risk factors among pregnant women abused by their partners. Violence Against Women, 10, 498-513.

10. Eisenstat, S. A., \& Bancroft, L. (1999). Domestic violence. New England Journal of Medicine, 341, 886-892.

11. Parsons, L., Goodwin, M. M., \& Petersen, R. (2000). Violence against women and reproductive health: Toward defining a role for reproductive health care services. Maternal and Child Health Journal, 4, 135-140.

12. Liebschutz, J., Frayne, S., \& Saxe, G. (2003). Violence against women: A physician's guide to identification and management. Philadelphia, PA: ACP-ASIM Press.

13. Olson, L., Anctil, C., Fullerton, L., Brillman, J., Arbuckle, J., \& Sklar, D. (1996). Increasing emergency physician recognition of domestic violence. Annals of Emergency Medicine, 27, 741-746.

14. Rand, M. R. (1997). Violence-related injuries treated in hospital emergency departments. Bureau of Justice Special Report, \#NCJ156921. Washington, DC: US Department of Justice, Office of Justice Programs.

15. El-Bassel, N., Gilbert, L., Krishnan, S., et al. (1998). Partner violence and sexual HIV-risk behaviors among women in an inner-city emergency department. Violence and Victims, 13, 377-393. 
16. Coker, A. L., Bethea, L., Smith, P. H., Fadden, M. K., \& Brandt, H. M. (2002). Missed opportunities: Intimate partner violence in family practice settings. Preventive Medicine, 34, 445-454.

17. Wu, E., El-Bassel, N., Witte, S. S., Gilbert, L., \& Chang, M. (2003). Intimate partner violence and HIV risk among urban minority women in primary health care settings. AIDS and Behavior, 7, 291-301.

18. Keeling, J., \& Birch, L. (2004). The prevalence rates of domestic abuse in women attending a family planning clinic. The Journal of Family Planning and Reproductive Health Care, 30, 113-114.

19. Family Violence Prevention Fund. National Consensus Guidelines on identifying and responding to domestic violence victimization in health care settings. (2004) SanFrancisco, CA: Family Violence Prevention Fund.

20. Flitcraft, A. H., Hadley, S. M., Hendricks-Matthews, M. K., McLeer, S. V., Warshaw, C. (1992). Diagnostic and treatment guidelines on domestic violence. American Medical Association. http://www.vahealth.org/civp/projectradarva/AMADiag\&Treat Guide.pdf. Accessed August 20, 2008.

21. American College of Obstetrics and Gynecology. (2007). Violence Against Women Project. http://www.acog.org/departments/ dept_notice.cfm?recno=17\&bulletin=585. Accessed August 20, 2008.

22. Hamberger, L. K., \& Ambuel, B. (1998). Dating violence. Pediatric Clinics of North America, 45, 381-390.

23. Amar, A. F. (2004). Prevalence estimates of violence in the dating experiences of college women. Journal of National Black Nurses' Association, 15, 23-31.

24. Wingood, G. M., DiClemente, R. J., McCree, D. H., Harrington, K., \& Davies, S. L. (2001). Dating violence and the sexual health of black adolescent females. Pediatrics, 107, e72.

25. Raj, A., Silverman, J. G., \& Amaro, H. (2000). The relationship between sexual abuse and sexual risk among high school students: Findings from the 1997 Massachusetts Youth Risk Behavior Survey. Maternal and Child Health Journal, 4, 125-134.

26. Decker, M. R., Silverman, J. G., \& Raj, A. (2005). Dating violence and sexually transmitted disease/HIV testing and diagnosis among adolescent females. Pediatrics, 116, e272-e276.

27. Shrier, L. A., Pierce, J. D., Emans, S. J., \& DuRant, R. H. (1998). Gender differences in risk behaviors associated with forced or pressured sex. Archives of Pediatrics and Adolescent Medicine, $152,57-63$.

28. Kahn, J. A., Huang, B., Rosenthal, S. L., Tissot, A. M., \& Burk, R. D. (2005). Coercive sexual experiences and subsequent human papillomavirus infection and squamous intraepithelial lesions in adolescent and young adult women. Journal of Adolescent Health, 36, 363-371.

29. Schoen, C., Davis, K., Collins, K., Greenberg, L., Des Roches, C., \& Abrams, M. (1997). The commonwealth fund survey of the health of adolescent girls. New York: The Commonwealth Fund.

30. Jacoby, M., Gorenflo, D., Black, E., Wunderlich, C., \& Eyler, A. E. (1999). Rapid repeat pregnancy and experiences of interpersonal violence among low-income adolescents. American Journal of Preventive Medicine, 16, 318-321.

31. Ashley, O. S., \& Foshee, V. A. (2005). Adolescent help-seeking for dating violence: Prevalence, sociodemographic correlates, and sources of help. Journal of Adolescent Health, 36, 25-31.

32. Juszczak, L., Melinkovich, P., \& Kaplan, D. (2003). Use of health and mental health services by adolescents across multiple delivery sites. Journal of Adolescent Health, 32S, 108-118.

33. Zimmer-Gembeck, M. J., Alexander, T., \& Nystrom, R. J. (1997). Adolescents report their need for and use of health care services. Journal of Adolescent Health, 21, 388-399.
34. Britto, M. T., Klostermann, B. K., Bonny, A. E., Altum, S. A., \& Hornung, R. W. (2001). Impact of a school-based intervention on access to healthcare for underserved youth. Journal of Adolescent Health, 29, 116-124.

35. Vingilisa, E., Wade, T., \& Seeley, J. (2007). Predictors of adolescent health care utilization. Journal of Adolescence, 30(5), 773-800.

36. Wolk, L. I., \& Kaplan, D. W. (1993). Frequent school-based clinic utilization-A comparative profile of problems and service needs. Journal of Adolescent Health, 14(6), 458-463.

37. Rickert, V. I., Wiemann, C. M., Harrykissoon, S. D., Berenson, A. B., \& Kolb, E. (2002). The relationship among demographics, reproductive characteristics, and intimate partner violence. American Journal of Obstetrics and Gynecology, 187, 10021007.

38. Zeitler, M. S., Paine, A. D., Breitbart, V., et al. (2006). Attitudes about intimate partner violence screening among an ethnically diverse sample of young women. Journal of Adolescent Health, 39, 119.e1-119.e8.

39. Milan, S., Lewis, J., Ethier, K., Kershaw, T., \& Ickovics, J. R. (2005). Relationship violence among adolescent mothers: Frequency, dyadic nature, and implications for relationship dissolution and mental health. Psychology of Women Quarterly, 29, 302-312.

40. Center for Impact Research. Domestic Violence and Birth Control Sabotage: A Report from the Teen Parent Project. (2000). Chicago: Center for Impact Research.

41. Ghanem, K. G., Hutton, H. E., Zenilman, J. M., Zimba, R., \& Erbelding, E. J. (2005). Audio computer assisted self interview and face to face interview modes in assessing response bias among STD clinic patients. Sexually Transmitted Infections, 81, 421-425.

42. Metzger, D. S., Koblin, B., Turner, C., et al. (2000). Randomized controlled trial of audio computer-assisted self-interviewing: Utility and acceptability in longitudinal studies. HIVNET Vaccine Preparedness Study Protocol Team. American Journal of Epidemiology, 152, 99-106.

43. Abbey, A. (2005). Lessons learned and unanswered questions about sexual assault perpetration. Journal of Interpersonal Violence, 20, 39-42.

44. Oksenberg, L., Vinoku, A., \& Cannell, C. (1979). The effects of commitment to being a good respondent on interview performance. In C. Cannell, L. Oksenberg, \& J. Converse (Eds.), Experiments in interviewing techniques. Washington, DC: Department of Health Education and Welfare.

45. Ford, C. A., Bearman, P. S., \& Moody, J. (1999). Foregone health care among adolescents. JAMA, 282, 2227-2234.

46. Ware, J. E., Kosinski, M., \& Keller, S. D. (1996). A 12-item short-form health survey: Construction of scales and preliminary tests of reliability and validity. Medical Care, 34(3), 220-233.

47. Goodman, E. (1999). The role of socioeconomic status gradients in explaining differences in US adolescents' health. American Journal of Public Health, 89, 1522-1528.

48. Straus, M. A., Hamby, S. L., Boney-McCoy, S., \& Sugarman, D. B. (1996). The revised conflict tactics scales (CTS2). Journal of Family Issues, 17, 283-316.

49. Koss, M. P., \& Gidycz, C. A. (1985). Sexual experiences survey: Reliability and validity. Journal of Consulting and Clinical Psychology, 53(3), 422-423.

50. SAS [computer program] (2009) Version 9. Cary, NC: SAS Institute Inc. 